\title{
AS NOVAS INSTITUCIONALIDADES DO TRABALHO NO SETOR PÚBLICO: OS AGENTES COMUNITÁRIOS DE SAÚDE
}

THE NEW INSTITUTIONALITIES OF WORK IN THE PUBLIC SECTOR:THE COMMUNITY HEALTH AGENTS

Jacob Carlos Lima ${ }^{1}$

Fernanda Flávia Cockell ${ }^{2}$

Resumo $\mathrm{O}$ artigo analisa o surgimento dos agentes comunitários de saúde como categoria de trabalhadores num contexto de flexibilização das relações de trabalho, numa dupla direção: na valorização da atividade do trabalho, maior autonomia, formação continuada e valorização de habilidades sociais como elementos primordiais na implementação de serviços sociais pelo Estado; e no caráter atípico representado por contratos de trabalho fora da estabilidade do funcionalismo, condição para a atividade desenvolvida, por um lado, e, por outro, fator de vulnerabilidade social do trabalhador pela preponderância de contratos de subcontratação, informais e outros marcados pela instabilidade da relação de trabalho.

Palavras-chave trabalho flexível; trabalho atípico; vulnerabilidade social; agentes comunitários de saúde.
Abstract The article analyses the appearance of community health agents as a worker category in a context of labor relation flexibilization, in a double sense: valuing work, greater autonomy, continued education, and social skills as primordial elements in the State's implementation of social services; and the atypical character represented by labor agreements outside of the public servents' stability, a condition for the activity that is carried out, on one hand, and, on the other, a factor of social vulnerability of the worker by the preponderance of outsourcing and informal agreements, among others, which are marked by unstable work ties.

Keywords Flexible work; atypical work; social vulnerability; community health agents. 


\section{Introdução}

Este artigo busca analisar o surgimento de um trabalhador atípico, os agentes comunitários de saúde, num contexto de flexibilização das relações de trabalho e da reconfiguração da ação estatal nas políticas públicas. Essa reconfiguração valoriza a maior participação da comunidade no controle dessas políticas e de um profissional igualmente vinculado a essa comunidade como forma de intermediar adequadamente a equipe de saúde e a população assistida, possibilitando maior eficácia nos serviços prestados. Em termos de relação de trabalho, permite grande autonomia ao profissional e uma formação continuada, mas essa positividade não se traduz em contratos de trabalho que garantam um mínimo de segurança e acesso aos direitos sociais a esses trabalhadores. Essa dualidade presente na construção por excelência de um trabalhador flexível, com requisitos sociais entendidos em sua funcionalidade no desempenho da atividade de trabalho, reflete os dilemas das transformações capitalistas recentes, nas quais a maior participação ou mesmo valorização de atributos do trabalho vem acompanhada de uma precarização de contratos de trabalho e aumento da vulnerabilidade social.

\section{Flexibilização, terceirização e informalização}

As mudanças políticas e econômicas das últimas décadas alteraram substancialmente as relações capital-trabalho e, conseqüentemente, as relações entre classes e sujeitos sociais.

Entre essas mudanças, podemos destacar as novas tecnologias de produção, a microeletrônica, a telemática, que revolucionaram os processos produtivos, a comunicação em tempo real, favorecendo as trocas financeiras nos mercados globais, a configuração da sociedade em redes e a descentralização produtiva das atividades de serviço públicos e privados.

Esse conjunto de fenômenos vem agrupado no conceito globalização ou mundialização e tem afetado todos os setores econômicos, a vida social e política e pode ser caracterizado, seguindo a escola regulacionista francesa, como acumulação flexível (Lipietz, 1991; Harvey, 1993). Para essa escola, um regime de acumulação é uma forma de periodização do capitalismo na qual são reguladas as relações entre capital e trabalho. A acumulação flexível se contraporia à rigidez fordista, marcada na produção pelo taylorismofordismo e forte presença estatal na economia e na reprodução social, tendo como modelo o estado de bem-estar social. Neste, a relação salarial incorpora uma série de benefícios para o trabalhador, com o trabalho se constituindo na origem de numerosos direitos sociais o que ficou conhecido como cidadania salarial. 
Geralmente, flexibilização vem acompanhada de mais duas referências: desregulamentação - eliminação de entraves legais que comprometeriam a lucratividade do capital e representariam custos, como direitos trabalhistas, políticas de protecionismo industrial ou de serviços e regulações variadas da atividade econômica; e precarização, as conseqüências, para os trabalhadores, da desregulamentação - sinônimo, em grande medida, da eliminação das regras do mercado de trabalho e dos direitos sociais integrantes destas regras.

As transformações acima referidas na produção - novas tecnologias de produção e organizacionais - eliminaram postos de serviço e qualificações profissionais e redistribuíram as unidades produtivas globalmente, resultando na eliminação de empregos industriais diretos com o fim das grandes unidades fabris, agora desnecessárias; terceirização de serviços e processos em redes de empresas; decadência de antigas áreas industriais; e enfraquecimento da organização dos trabalhadores.

A crise do movimento sindical insere-se nas conseqüências dessas mudanças. Os sindicatos perderam filiados com o fechamento contínuo de unidades industriais e redução de postos de serviço. De uma situação de luta por melhores salários e condições de trabalho, passaram a reivindicar a manutenção de empregos e direitos. O medo do desemprego atenuou a capacidade combativa. Mais e mais empresas se transferem para áreas com baixa atividade sindical, com mão-de-obra barata e fartos incentivos fiscais propiciados pelo Estado.

A desregulamentação dos mercados de trabalho, ou pelo menos sua tentativa, não tem sido homogênea e conta ainda com uma grande resistência na sociedade civil. Entretanto, mecanismos diversos têm sido utilizados para a desregulamentação, se não de direito, de fato.

Entre eles, podemos nos referir à retomada, agora com ares de modernização, da velha subcontratação, presente desde os primórdios do capitalismo. Sucessora direta das velhas formas de trabalho a domicílio e equipes de empreitada, a subcontratação, também chamada agora de terceirização, insere-se na concepção de 'focalização' das empresas em uma atividade principal e a delegação para outras empresas das atividades complementares. Esse processo se dá em rede, as redes de subcontratação, que se inspiram no chamado modelo japonês. Neste modelo haveria uma relação virtuosa entre as empresas integrantes da rede, que se beneficiariam das inovações tecnológicas e investimentos de pesquisa da empresa primeira, beneficiando toda a rede. Como exemplos desse modelo, podemos citar empresas automobilísticas coreanas que inicialmente produziam para empresas japonesas e que, posteriormente, começaram a lançar produtos com marcas próprias.

No caso das empresas ocidentais, o modelo das empresas-rede se caracteriza por relações assimétricas entre compradores e fornecedores, a 
empresa mais poderosa estabelecendo as condições de compra, especificação de produtos etc., com a tal da virtuosidade mais 'virtual' que real.

A reestruturação produtiva, vista como adequação das empresas aos novos parâmetros da organização da produção voltada à competitividade dos mercados internacionais, junta a focalização ao 'enxugamento' das empresas, o que significa a eliminação de 'gorduras', leia-se mão-de-obra considerada excessiva e desnecessária. A intensificação do trabalho a partir das formas organizacionais participativas e a terceirização representam a busca de menores custos nos lugares em que isso é possível. Com isso, temos também a desterritorialização da produção, a fuga das empresas em regiões com tradições industriais e de trabalho organizado que agora tornaram-se caras para o capital e a instalação de filiais ou empresas terceirizadas em países com menos restrições ambientais, de regulação do trabalho e atividade sindical significativa que se integram aos fluxos do capitalismo global.

Nesse contexto, temos a recuperação igualmente de outro conceito, historicamente vinculado à precarização do trabalho e sinônimo, por muito tempo, de subdesenvolvimento econômico e atraso social: a informalidade, agora repensada também como trabalho flexível.

Discutida no final dos anos 60 e 70 como produto de modernizações incompletas dos países do terceiro mundo, com um exército de trabalhadores circulando entre o trabalho formal e o informal, a informalidade contribuiria para manter baixo o custo da força de trabalho, além de se constituir em um obstáculo na formação de identidades coletivas entre os trabalhadores pela instabilidade da sua condição enquanto classe (Oliveira, 1981). Além disso, os milhares de ambulantes vendendo quinquilharias industrializadas a uma população de baixa renda funcionariam indiretamente como distribuidores da indústria sem pagamento das taxas e impostos de comercialização; por fim, as empregadas domésticas que proviam, na ausência de serviços oferecidos pelo Estado, suporte à reprodução da força de trabalho para as camadas médias de emprego.

No final dos anos 80, a discussão sobre informalidade começou a ser deslocada. Foi vista como resultado da excessiva regulação estatal das economias latino-americanas e resultado da atuação de micro e pequenos empreendedores que, de certa forma, refletiriam o caráter dinâmico e o empreendedorismo sufocado pelo Estado (DeSoto, 1987).

Nos países de capitalismo avançado, a reestruturação produtiva e o crescimento do desemprego estrutural aumentaram a visibilidade das atividades informais, geralmente ocupadas por imigrantes. Estas foram analisadas inicialmente dentro das chamadas economias 'étnicas', representadas por grupos nacionais nos Estados Unidos e Europa e como estratégias de integração dos recém-chegados, assim como também a importação de procedimentos de dependência e clientelismo existentes nos países de 
origem. Entretanto, com o crescimento do desemprego e da extrapolação da informalidade dos guetos étnicos, as análises passaram a considerá-la no contexto dos processos de reestruturação econômica, do aumento da competividade mundial, da flexibilização e desregulamentação dos mercados de trabalho e do crescimento do desemprego estrutural (Portes, Castells, Benton, 1989).

Podemos situar, nesse momento, o debate do que poderíamos chamar de 'nova informalidade', que traz consigo toda a ambigüidade e polêmica do conceito anterior. A informalização como decorrente dos processos de flexibilização. Mas o que traz de novo? Milhares de trabalhadores escolarizados e qualificados que antes se encontravam no mercado formal, dispensados nos processos pela intensificação do trabalho com as mudanças organizacionais, pelos contratos temporários, por tempo parcial, pelos novos setores surgidos como a informática com um exército de trabalhadores fora de qualquer formalidade, na redução de hierarquias no trabalho, enfim, na desestabilização dos estáveis (Castel, 1998). Ao lado do muambeiro, do camelô, tradicionais trabalhadores informais e precários, têm os vários 'micreiros', consultores variados, 'bolsistas', o engenheiro vendedor de cachorro quente, o professor taxista, o ex-bancário perueiro etc.

A informalidade deixa de ser uma característica terceiro-mundista e torna-se um produto dos novos tempos flexíveis. Perde o caráter de negatividade anterior e assume a positividade, para o capital, da desregulamentação e flexibilização. A ausência de qualquer contrato se junta, na ambigüidade do conceito, a novas formas de institucionalidades marcadas pelo caráter temporário, restrito dos novos contratos. A condição salarial discutida pelo Castel (1998), na qual o assalariamento era uma relação social que incorporava direitos e regulamentações que limitavam a exploração da força de trabalho e previa todo um sistema de proteção, dá lugar, novamente, ao 'livre mercado'. Os trabalhadores mais organizados, com melhor capital cultural e melhor situação de mercado, mantêm direitos (embora restringidos, na maioria dos casos) enquanto os demais ficam ao sabor do mercado. O Estado intervém, possibilitando os novos contratos, ou mesmo nenhum contrato, no discurso da modernidade e competitividade internacional. O custo Brasil - no qual apenas o salário e as obrigações sociais são destacados - é apresentado como um dos problemas da competitividade da indústria nacional. A ineficácia da ação estatal em nosso 'estado de mal-estar social' é apontado como algo a ser eliminado para que o trabalhador ganhe mais e as empresas idem. Em outras palavras, diminuir o custo Brasil, para os empresários, é cortar direitos sociais. Dentro das novas institucionalidades no setor público e privado, podemos nos referir aos contratos de consultoria, empresas de fornecimento de mão-de-obra, cooperativas de produção e trabalho, trabalho em ONGs, associações, organizações da sociedade civil de interesse 
público (Oscips), constituições das chamadas organizações públicas mas não estatais e variações da informalidade pura e simples representadas por 'termos de adesão' a determinadas atividades.

Embora o arcabouço ideológico neoliberal que acompanha esse processo esteja em crise, após seu auge nos anos 80 e 90, com o reconhecimento da necessidade da ação estatal na organização do desenvolvimento econômico e social, essa recuperação está longe de significar um retorno a uma situação anterior de regulação e centralização de políticas públicas.

A Constituição de 1988, marco na redemocratização do país, representou os anseios da sociedade civil de maior participação nas instâncias decisórias. Entre suas características encontra-se a co-responsabilização dos diversos níveis de governo e sociedade civil no controle das políticas públicas, significando maior participação popular nessas políticas e maior descentralização da atividade estatal.

A reforma do Estado, parcialmente realizada na década de 1990, significou a adoção do arcabouço neoliberal com a abertura econômica, a privatização de empresas, o enxugamento da atuação estatal no planejamento econômico e nas políticas sociais, entre outras medidas, tendo, em certa medida, a nova Constituição como referência. Por outro lado, assistiu-se à multiplicação de conselhos e outras formas participativas de representação da sociedade na formulação-controle de políticas. De forma paradoxal, a descentralização foi defendida pela direita e esquerda no espectro político nacional. Pela direita, na busca pela redução da presença estatal na economia e sua adequação em termos de eficácia empresarial, e pela esquerda, preocupada com a maior democratização do aparelho estatal.

Dentro das mudanças na atuação estatal, nos interessa analisar como as relações de trabalho são pensadas a partir do discurso da co-responsabilização da sociedade no controle das políticas públicas, tendo como referência a proposta de eficácia das políticas, focalização e universalização, e flexibilização dos contratos de trabalho, como forma de compreender os novos formatos assumidos pelo emprego público num contexto de flexibilização econômica.

Nessa perspectiva, vale destacar mudanças no emprego público como paradigmáticas dessas transformações. Embora não tenha havido a perda sistemática do caráter fordista presente no emprego público, como estabilidade para o concursado, esta estabilidade, conforme a carreira, sofreu modificações, seja pelo aumento dos períodos probatórios, no qual o funcionário pode ser demitido, seja pela redução dos empregos resultante da terceirização de serviços das autarquias, fundações e empresas públicas, pelo crescimento do trabalho temporário permitido pela lei, além das demissões que passam a ser permitidas a partir de excesso de contingente, entre outros motivos. 
Krein (2007) demonstra que entre 1995 e 2005 houve um crescimento das formas de contratação dos servidores não-efetivos de 8,9\%, em 1995, para 18,3\%, em 2005, contrariando a lógica das decisões da Constituição de 1988 e do Regime Jurídico Único3, que estabeleciam o concurso público como forma de ingresso no serviço público. Há igualmente o aumento da terceirização, não apenas nas formas de contratação, como também na externalização de serviços públicos nas três esferas do governo (municipal, estadual e federal), motivado por: promessa de eficácia e eficiência dos métodos de gestão privada, verificados posteriormente como inadequados devido às especificidades do setor público; possibilidade de driblar a Lei de Responsabilidade Fiscal, uma vez que os gastos com terceirização não são calculados como despesa com pessoal; facilidade dos administradores em 'manusear' a força de trabalho terceirizada em prol das suas finalidades políticas e administrativas; e inexistência de investimentos, corroborando com o mecanismo de financiamento das campanhas eleitorais. A flexibilização das formas de contrato de trabalho no setor público acontece ainda por meio de contratos por tempo determinado, viabilizados por legislações específicas que possibilitam contratações emergenciais na saúde e na educação, nesta para suprir a falta de professores concursados, e em outras áreas, de acordo com as necessidades imediatas de fundações públicas e autarquias.

De acordo com Biavaschi (2005), as reformas administrativas (projeto de emenda constitucional (PEC) n. ${ }^{\circ}$ 41/97), da Previdência (PEC 33/96) e do Judiciário (PEC 112/95) corroboraram com a flexibilização e fragilização do emprego público. A reforma administrativa, além de permitir a contratação pelo regime da CLT (Consolidação das Leis Trabalhistas), flexibilizando a regra geral de ingresso por concurso público, incluiu regras que permitiam a terceirização no serviço público por meio da quebra de princípios, como:

O da isonomia da remuneração; o da estabilidade do servidor público, permitindo a despedida por insuficiência de desempenho, mediante procedimento simplificado de avaliação periódica, ou para redução do quadro aos limites definidos em lei complementar para gastos com pessoal; e o da irredutibilidade dos vencimentos (Biavaschi, 2005, p. 311).

Este período é, portanto, marcado pela introdução de novas regulamentações que ampliaram a flexibilidade nas formas de contratação do emprego público. Na área de saúde pública, Nogueira $(1996$; 1999) afirma que o Sistema Único de Saúde (SUS) passou na década de 90 por uma "reforma informal do Estado", com múltiplas configurações de terceirização de serviços finais através de empresas privadas, de cooperativas de funcionários, cooperativas de agentes comunitários etc. A contratação flexível no SUS se dá 
pelo uso indiscriminado de contratos temporários, cargos comissionados, vinculação informal através de bolsas de trabalho ou pro labore, 'código 7'4 e artifícios similares, normalmente mediada por meio do recurso de 'triangulação' da gestão de pessoas em parceria com fundações de apoio, ONGs vinculadas ao Estado e outras entidades.

Vale destacar, igualmente, mudanças em empresas estatais como Banco do Brasil, que se adequou ao mercado de trabalho privado, perdendo as características que marcaram a carreira dos bancários a ele vinculados por décadas e seu diferencial em termos salariais e de direitos. Nessa perspectiva, podemos falar da atuação estatal favorecendo a flexibilização dos mercados seja nas tentativas de mudar a legislação, seja na prática na atuação efetiva de seus diversos órgãos que passam a utilizar trabalho flexível, institucionalizado ou não, legitimando em certa medida novas formas de utilização do trabalho dentro da nova lógica que acompanha essas mudanças: a lógica do mercado, não do produtor, mas do consumidor. A lógica privada na prestação dos serviços do Estado, da eficiência e da eficácia na implementação de políticas públicas.

Como forma de demonstrar essa aproximação flexibilização e novas institucionalidades no trabalho, tendo como referência o emprego público, vamos nos referir ao Programa Saúde da Família (PSF), agora Estratégia Saúde da Família (ESF), exitoso nacionalmente e que sintetiza o novo nas relações de trabalho e na atuação estatal. Iremos nos referir ao Programa Saúde da Família de 1994 e, mais especificamente, ao programa que lhe antecedeu e que ainda o integra: o Programa de Agentes Comunitários de Saúde (Pacs). Documento produzido pelo Instituto de Pesquisa Econômica Aplicada (Ipea) sobre as novas formas de contratação pelo Estado destaca que o Pacs/PSF representaria um novo paradigma das políticas sociais, que pressupõe uma articulação entre os princípios do Estado e da comunidade com prevalência desta última, que substitui o Estado-empresário neoliberal, presente na discussão inicial da reforma do Estado (Nogueira, Silva e Ramos, 2000).

\section{O trabalhador da comunidade para a comunidade}

O trabalho dos agentes comunitários de saúde (ACS) surge nos anos 90, inserido num contexto de transformação do trabalho marcado pela implementação de políticas sociais descentralizadas pelo Estado, utilização de trabalhadores fora do quadro do funcionalismo tradicional e expansão das relações de trabalho atípicas.

Dezessete anos já se passaram desde a inserção dos ACS na rede do SUS. Em 1991, um estudo piloto desenvolvido pelo Ministério da Saúde no estado da Paraíba cria o Programa de Agentes Comunitários de Saúde, com a 
proposta de reorganização da atenção básica em saúde por meio da ação dos ACS, profissionais encarregados de mediar e articular o serviço de saúde com a comunidade onde vive e trabalha. Segundo Lima e Moura (2005), a fundamentação do PACS encontra-se em programas que foram experimentados em diversas regiões do país anteriormente.

Após três anos, houve a transição do Pacs para o PSF, no qual os ACS atuam desde 1994, ano de implantação do programa pelo Ministério da Saúde. Devemos considerar que o Pacs foi baseado em experiências anteriores no trabalho de agentes, como o Médico da Família, de Niterói, os Agentes Pastorais da Igreja Católica e visitadoras sanitárias do Serviço Especial de Saúde Pública (Sesp) ${ }^{5}$. Entretanto, a experiência que se tornou modelo, por sua proximidade, foi a do Programa de Agentes de Saúde do governo do estado do Ceará a partir de 1987, voltado ao combate dos efeitos da seca e que obteve grande êxito na redução da mortalidade infantil (Lima e Moura, 2005). Com isso, podemos afirmar que há mais de duas décadas o papel do agente comunitário de saúde vem sendo ampliado, atuando no mapeamento, no diagnóstico de saúde da comunidade e no desenvolvimento de ações de promoção e proteção à saúde.

A evolução do número de ACS no período entre 1994 e 2008 é expressiva, representando um crescimento significativo de postos de trabalho. Hoje, trabalham em todo o Brasil 221.588 agentes comunitários de saúde, totalizando até 12 agentes por cada equipe (Valadares, 2008). De acordo com o Sistema de Informações da Atenção Básica (Brasil, 2005), em 1999, cinco anos após a criação do PSF, o programa já contava com 104.215 agentes e, uma década depois, este número já alcançava, em 2003, a marca de 184.341 agentes.

Em 2008, o SUS completa vinte anos e o Programa Saúde da Família 15 anos, contabilizando mais de 103 milhões de brasileiros acompanhados por 28.452 equipes de Saúde da Família. A saúde da família é um modelo de atenção básica em saúde. Estruturada, inicialmente, como um programa, passou a ser considerada pelo Ministério da Saúde como uma estratégia estruturante dos sistemas municipais de saúde, cujo principal propósito é reorientar o modelo assistencial. Este modelo rompe com o paradigma biomédico, superando a antiga proposição de caráter exclusivamente centrado na doença, ao desenvolver ações de promoção e proteção à saúde da comunidade, concomitantemente ao atendimento domiciliar para a recuperação, reabilitação de doenças e agravos mais freqüentes.

Desenvolve-se por meio de práticas gerenciais e sanitárias e participativas, sob a forma de trabalho em equipes multiprofissionais6 (com, no mínimo, um médico de família, um enfermeiro, um auxiliar de enfermagem e seis agentes comunitários de saúde), dirigidas às populações de territórios delimitados ( 3 mil a 4 mil e 500 pessoas ou de mil famílias de uma 
determinada área), que passam a ter co-responsabilidade no cuidado à saúde (Brasil, 2008).

A saúde é entendida como produção social, como "um processo construtivo que uma coletividade pode conquistar em seu dia-a-dia" (Andrade e Inojosa, 2004). Sendo assim, para atingir os princípios e bases operacionais do PSF, é preciso que a equipe tenha conhecimento sobre a realidade da população que atende e as organizações familiares e comunitárias, com ênfase nas suas características sociais, econômicas, culturais, demográficas e epidemiológicas.

É neste contexto que os agentes comunitários de saúde se inserem, como os atores sociais que intermedeiam a relação entre a comunidade e os demais membros da equipe de saúde. Espera-se que o agente conviva com a realidade e as práticas de saúde do bairro onde mora e trabalha, mostrandose capaz de apreender a dinâmica social da comunidade, suas necessidades, potencialidades e limites (Brasil, 2008).

Segundo Nunes et al. (2002, p. 1.640), existe um movimento “bidirecional dos agentes", pois, ao mesmo tempo em que instruem a população "modos de fazer estabelecidos pelo sistema médico oficial", fornecem aos profissionais de saúde "elementos chaves para a compreensão dos problemas de saúde das famílias e das necessidades da população".

Os ACS são profissionais que aliam na sua atividade de trabalho as dimensões 'saber-fazer' (domínio prático) e 'saber-conhecer' (domínio cognitivo), voltadas tanto para atividades de promoção da saúde, através da prevenção de doenças, da mobilização de recursos e das práticas sociais de promoção da vida e cidadania, quanto para a orientação de indivíduos, grupos e populações, com características de educação popular em saúde e acompanhamento de famílias (Brasil, 2004).

Os ACS são considerados, por Lima e Moura (2005), trabalhadores atípicos devido às peculiaridades dos contratos de trabalho e às exigências de 'capital social' para o desempenho da ocupação. Os autores sugerem que uma característica singular dessa categoria de trabalhadores está no fato de:

Pertencerem à comunidade em que atuam, sem exigências de um conhecimento técnico específico. Este pertencimento pressuporia uma familiaridade com os problemas da comunidade, o que permitiria atuar com maior eficiência e conquistar a confiança dessa população. Em outros termos, são trabalhadores selecionados a partir do capital social que dispõem, o que facilitaria os objetivos dos Programas voltados à obtenção de informações gerais de higiene e saúde e o atendimento básico em saúde da população (Lima e Moura, 2005, p. 104).

Outra particularidade destacada pelos autores é o controle social exercido pela comunidade, permanentemente informada dos seus direitos, das 
visitas obrigatórias dos agentes às suas residências, que podem denunciar os profissionais relapsos em suas obrigações. O fato de pertencerem à comunidade aumentaria sua visibilidade junto aos moradores e, por conseguinte, a responsabilidade no atendimento. A interiorização pelos agentes de uma identidade comum territorializada com a população atendida intensifica a disciplina do trabalhador frente à autonomia do trabalho realizado, acompanhado pelas equipes e pela comunidade.

O capital social dos ACS tem um papel fundamental para o alcance dos objetivos da estratégia em Saúde da Família, onde a confiança da população no profissional será fundamental para o êxito de campanhas preventivas promovidas pelo ministério e secretarias de saúde, bem como para o cadastramento domiciliar, para a realização de ações dirigidas aos problemas de saúde de maneira pactuada com a comunidade onde atua, para o cuidado dos indivíduos e das famílias e para ter uma postura proativa frente aos problemas de saúde-doença da população (Lima e Moura, 2005). Conceito polêmico e de uso sistemático pelo Banco Mundial a partir dos anos 90 na análise de políticas públicas e suas possibilidades, o capital social refere-se às redes sociais informais estabelecidas entre os indivíduos que podem estar referenciadas à vida em comunidade, ou não, mas que significa um conhecimento comum e sentido de participação, um conjunto de normas de reciprocidade estabelecida na vida cotidiana, entre as quais os laços de confiança se desenvolvem e atuam. Decorre das redes de sociabilidade integradas pelos indivíduos, propiciando conhecimento e informações fora da racionalidade burocrática (Lima e Moura, 2005)7

De acordo com o Ministério de Saúde, cabe aos ACS “orientar as famílias para a utilização adequada dos serviços de saúde" e, ao mesmo tempo, "informar os demais membros da equipe de saúde acerca da dinâmica social da comunidade, suas disponibilidades e necessidades" (Brasil, 1998, p. 18). Portanto, na dinâmica do trabalho do agente comunitário de saúde é freqüente existirem conflitos entre a dimensão técnica assistencial e a dimensão solidária e social (Nogueira, Silva, e Ramos, 2000). Os trabalhadores vivenciam, em seu cotidiano, situações contraditórias representadas, por um lado, pelo prestígio, conhecimento e poder que adquirem junto à comunidade; por outro, o desgaste de absorver as insatisfações da comunidade com o serviço de saúde e mesmo com demandas sociais mais amplas, com possibilidades reduzidas de resolução.

Bornstein e Stotz (2008), analisando a bibliografia sobre os ACS, verificaram que, apesar de críticas e restrições variadas sobre o alcance e os limites do programa8, o papel de mediação dos agentes é apontado de forma praticamente unânime como uma qualidade da proposta: o elo entre o serviço e a comunidade; a conjunção entre o saber popular e o conhecimento científico. 
Desde 10 de julho de 2002, o ACS tornou-se categoria profissional por meio da lei federal n. ${ }^{\circ}$ 10.507, após disputas de interesse sobre o mercado de trabalho e controle do exercício profissional (Bachilli, Scavassa e Spiri, 2008). Pode ser contratado diretamente pelo Estado, por concurso público, ou de forma terceirizada, por meio de organizações não-governamentais, organizações civis de interesse público, associações, sindicatos etc., sob o regime da CLT, sem a realização de concurso.

A seleção do ACS vem acontecendo de formas variadas, seja através de concurso público, concurso simplificado, indicação, termo de adesão, seleção popular, entre outras pouco explícitas. Configuram-se na atualidade múltiplas formas de contratação, como: cargo efetivo, cargo comissionado, emprego, contratos temporários, contrato verbal, vínculo informal, cooperado, prestador de serviço, bolsista e outros (Brasil, 2008). Existem no mínimo dez diferentes formas de inserção, segundo o levantamento realizado pelo Departamento de Atenção Básica (DAB), entre julho de 2001 e agosto de 2002 (Brasil, 2008). Castro, Villar e Fernandes (2004, p. 2) apontam que tal diversidade ocasiona problemas para os ACS e para a gestão do trabalho. Ocorrem conflitos e incertezas e, principalmente, criam-se expectativas de regulação estatal.

Além da multiplicidade de formas de contratação, existem outras particularidades de acordo com o ano de inserção no PSF. Os agentes que começaram a atuar antes de 2002 tinham que residir na comunidade há pelo menos dois anos, conforme a portaria n. ${ }^{\circ} 1.886 / 1997$. A partir da lei $\mathrm{n}^{\mathrm{o}} 10.507 / 2002$, o ACS apenas precisa residir na microarea para início e continuidade do exercício profissional. Além disso, passou-se a exigir do ACS ter concluído o ensino fundamental e não mais apenas saber ler e escrever, bem como concluir um curso de qualificação básica.

Com a regulação da formação do agente comunitário de saúde, o Ministério da Saúde procurou delinear uma concepção de formação que possibilitasse a elevação da escolaridade do ACS e de seu perfil de desempenho profissional. O Referencial Curricular para Curso Técnico de Agente Comunitário de Saúde, publicado em 2004, em parceria com o Ministério da Educação, propôs que a formação do ACS não seja limitada apenas ao módulo de Educação Básica. Por meio de um processo de educação contínua, o Ministério da Saúde espera que os ACS consigam aumentar o vínculo entre as equipes de saúde e as famílias/comunidade e avancem em direção à autonomia dos sujeitos em relação à própria saúde e à responsabilização coletiva pela promoção da saúde de indivíduos, grupos e meio ambiente (Brasil, 2004).

Morosini, Corbo e Guimarães relataram que em 2007 mais de 200 mil ACS estavam em formação ou em vias de começar o curso nas Escolas Técnicas do SUS (Etsus) de todo o país, visando à profissionalização técnica. As 
autoras consideram que a formação técnica dos ACS, por si só, "não é garantia de que não se incorra numa formação instrumentalizadora, agora, com o status tecnificado" (Morosini, Corbo e Guimarães, 2007, p. 272). Consideram que para evitar este status é imperioso que essa formação técnica "parta do entendimento da educação como um conjunto de práticas sociais que se articulam, baseadas nas ciências, constituindo uma formação que, além de técnica, precisa ser ética e política no sentido de se aproximar da formação humana" (Morosini, Corbo e Guimarães, 2007, p. 273).

Diante destas particularidades, a questão sobre as novas institucionalidades no trabalho dos ACS ganha evidência no meio acadêmico e nas entidades nacionais e municipais envolvidas com a Estratégia Saúde da Família, devido, principalmente, à discussão sobre o tipo de vinculação institucional 9 deste profissional.

A polêmica acontece tanto devido aos altos índices de informalidade dos ACS quanto pelas controvérsias existentes sobre a possibilidade dos ACS serem contratados como servidores públicos, encarada como “inadequada para uma função que exige um relacionamento estreito e permanente com a comunidade onde esses trabalhadores são recrutados" (Nogueira, Silva e Ramos, 2000, p. 1).

Com a criação da Lei de Profissão de Agente Comunitário de Saúde pelo Governo Federal (lei n. ${ }^{\circ}$ 10.507, de 10 de julho de 2002), os ACS ganharam a legitimação da profissão, contudo a regulamentação não significou o reconhecimento de direitos que dependem da natureza jurídica da contratação, o que redireciona a discussão para formas de contratação, na qual está fora de cogitação o contrato nos quadros do funcionalismo. Seja pela especificidade citada da função, seja agora nas novas prioridades de contratação determinadas pelo Estado dentro do novo contexto social.

De acordo com Castro, Villar e Fernandes (2004, p. 2), a lei n. ${ }^{\circ} 10.507$ de 2002 não deu aos ACS “a condição de serem institucionalizados com direitos trabalhistas garantidos", permanecendo sem acesso a férias, décimo terceiro salário, seguro- desemprego, aposentadoria, entre outros.

Estudos recentes realizados em municípios de São Paulo, Paraíba, Pernambuco e Rio Grande do Norte (Santos et al., 2008; Lima e Moura, 2005; Nascimento, 2005; Castro, Vilar e Fernandes, 2004) constataram que, dentro da diversidade de formas de vinculação de trabalho realizadas entre as secretarias de saúde dos municípios e os ACS, prevalecem ainda os contratos temporários. Ressalte-se, entretanto, a diversidade de situações em todo o país. Apenas como exemplo, podemos citar o caso de Curitiba, onde os ACS conquistaram o adicional de insalubridade, acrescendo até $20 \%$ sobre o salário (Câmara Municipal de Curitiba, 2005). 
Diante deste quadro desigual, o Governo Federal vem buscando alternativas para incentivar a redução da precariedade dos contratos de trabalho dos ACS. O Ministério da Saúde aumentou, no final de 2007, em 40\% o valor mensal dos incentivos repassados aos municípios por agente em atividade na expectativa de conseguir incentivar à formalização dos vínculos trabalhistas dos ACS, na medida em que cria condições financeiras para que os gestores passem a arcar com todos os direitos trabalhistas. Como aumento, o valor da parcela assumida pelo Ministério da Saúde no pacto tripartite aumenta de $\mathrm{R} \$ 300,00$ para $\mathrm{R} \$ 523,00$. Os incentivos garantem, exclusivamente, o pagamento pelo município do salário mensal e $13^{\circ}$ salário do ACS.

Entretanto, é fundamental percebermos que não se trata, exclusivamente, de uma questão financeira. Sabe-se que o custo para a formalização do vínculo trabalhista do ACS, para cobrir encargos da seguridade social, é próximo de $20 \%$, porém, mesmo com o repasse realizado pelo governo, é importante ressaltarmos as implicações para as funções desempenhadas pelos agentes, o tornar-se funcionário perdendo em grande medida a interface comunitária e de controle social referente à ocupação (Brasil, 2007).

Lima e Moura (2005) afirmam que, em termos da organização do trabalho, a flexibilidade configura-se 'positiva', ao permitir às equipes de trabalhadores margens de autonomia e qualificação continuada e participação ativa, uma vez que os ACS são valorizados por fazerem parte da comunidade. Por outro lado, se considerarmos as relações de trabalho, a flexibilidade é 'negativa', prevalecendo contratos temporários, parciais ou mesmo inexistentes. Os autores verificaram que, no Nordeste, existiam ACS que trabalharam cerca de 14 anos como 'trabalhadores precários'.

Outro aspecto relevante é a forma de seleção dos ACS, direta ou indireta. A contratação direta pelo município pode ocorrer: a) para cargo público efetivo: mediante concurso público; b) para emprego público: também mediante concurso público; c) cargo em comissão (atualmente inviabilizado para ACS pela nova redação do art.37, inciso V, da Constituição Federal). A contratação indireta se dá mediante contrato, convênio ou termo de parceria com entidade de direito privado. De acordo com o Ministério de Saúde (Brasil, 2002), a escolha dos ACS não deveria ocorrer sem qualquer procedimento prévio seletivo, mas, por outro lado, não é recomendável o procedimento clássico do concurso público, modelo este que não valoriza os critérios de liderança e solidariedade, imprescindíveis para o exercício dos ACS, uma vez que analisa exclusivamente o conhecimento formal do candidato. Apesar de não ser a forma recomendada pelo Ministério da Saúde, difundiu-se o modelo de seleção por concurso público em todo o território brasileiro a partir das demandas dos ACS e de partidos ou lideranças políticas mais sensíveis à instabilidade dos contratos desses profissionais. 
Uma busca preliminar em um site sobre concursos públicos - PCI Concursos - mostrou 893 notícias sobre vagas para ACS só para o ano vigente de 200810 . Falta verificar com mais vagar, entretanto, como os editais para seleção dos agentes estão sendo redigidos e se o processo seletivo público vem sendo realizado como alternativa ao concurso público. Por esse processo, o Estado recruta e contrata trabalhadores no regime celetista, sem direito à estabilidade.

De acordo com Santos (2008), a emenda constitucional n. ${ }^{\circ} 51$ (EC 51/06), publicada em 14 de fevereiro de 2006, dispõe sobre os agentes comunitários de saúde e agentes de combate às endemias, acrescentando os $\S \S 4^{\circ}, 5^{\circ}$ e $6^{\circ}$ ao artigo 198 da Constituição Federal. Amparada pela EC 51, a lei n ${ }^{\circ} 10.507$, de 2002, é revogada, sendo substituída pela lei n. ${ }^{\circ} 11.350$, de 5 de outubro de 2006, reproduzindo quase na totalidade a lei anterior e acrescentando novos artigos referentes à contratação dos agentes por meio da criação de empregos públicos.

Entre as principais mudanças ocorridas com a EC 51 e com a lei n. ${ }^{\circ} 11.350 / 06$, Santos (2008) destaca a obrigatoriedade de contratação no serviço público mediante processo seletivo (contrato regido pela CLT), a comprovação periódica de moradia na comunidade de atuação, a perda do cargo em caso de descumprimento dos requisitos específicos, a eliminação de pessoa jurídica interposta para a contratação dos agentes (entidades privadas com a Oscip), o vínculo temporário durante o período de formação dos agentes, sendo submetidos a uma segunda prova de avaliação ao final do curso e o reconhecimento do vínculo de emprego dos agentes contratados anteriormente à lei por interposta pessoa jurídica, desde que tenha ocorrido processo de seleção.

Santos (2008, p. 21) explica que a EC 51 utilizou a expressão 'processo de seleção pública' e não 'concurso público' com o intuito de atribuir um significado diferente, criando uma "espécie do gênero concurso", atribuindo maior simplicidade e agilidade à seleção pública de servidores. Ainda segunda a autora, os ACS deverão ser 'contratados', sob regime da CLT, não sendo nomeados para cargo público, sob regime estatuário.

Lima e Moura (2005) consideram que os processos seletivos organizados autonomamente pelas prefeituras desconsideram, por vezes, a vinculação comunitária, podendo favorecer fraudes na comprovação pelos candidatos da vinculação com a comunidade, e, também, as indicações políticas.

Acreditamos que à medida que se expandem as formas de seleção por seleção pública, o perfil dos ACS irá gradualmente se modificar, tanto no que diz respeito ao grau de educação formal destes profissionais quanto à abrangência do capital social por ele acumulado.

A literatura já sinaliza transformações no perfil deste profissional, ocasionada pelas mudanças estruturais na oferta de empregos, pelo aumento da 
concorrência e pela baixas médias salariais de algumas regiões. Santos et al. (2008) analisaram o perfil de 38 agentes que atuam em quatro municípios de pequeno porte do Noroeste Paulista e constataram que 5,3\% dos agentes possuem o ensino fundamental incompleto; $65,8 \%$, o ensino médio completo; 7,9\%, o ensino médio incompleto; e $21,1 \%$, o ensino superior incompleto. Estes dados apontam, portanto, para a elevação da escolaridade, uma vez que o requisito mínimo exigido é, de acordo com a lei n. ${ }^{\circ} 11.350$, de 2006, o ensino fundamental completo.

Santos et al. (2008) também identificaram que 65,8\% dos agentes atuam na área onde residem. Neste caso, acreditamos que, para os demais agentes $(34,2 \%)$, o sentimento de confiança e cumplicidade entre eles e a comunidade encontra-se comprometido. O capital social que facilitaria, segundo Lima e Moura (2005), os objetivos do PSF passa a não mais ser uma competência de todos os ACS, apesar de ainda ser exigido legalmente que os agentes morem na região que irão atuar. Outro fator apontado por Santos et al. (2008), que sinaliza mudanças no perfil dos ACS, é a alta rotatividade. Dos 38 agentes entrevistados, $47,4 \%$ estão a menos de um ano no PSF, fato esse considerado pelos autores desfavorável para a comunidade, pois compromete os vínculos e dificulta o estabelecimento de laços de confiança.

Diante da precariedade e flexibilidade das relações de trabalho, entendemos que, mesmo num contexto de crescente formalização dos contratos e aumento dos processos judiciais desses trabalhadores, reivindicando seus direitos trabalhistas, os ACS encontram-se num contexto de vulnerabilidade social, uma vez que a maior parte não tem acesso a direitos vinculados ao contrato de trabalho regular.

No cotidiano de trabalho, existem ainda outras particularidades no trabalho do ACS. Jardim (2007) mostra que, ao morar e trabalhar na mesma comunidade, o ACS atua durante 24 horas do dia, resultando, por vezes, em sofrimento psíquico para estes trabalhadores. Outros estudos sinalizam a ocorrência de diversos impasses no cotidiano de trabalho dos ACS, como, por exemplo, a necessidade de dominar conteúdos e práticas da biomedicina (Nunes et al., 2002), o convívio com o controle social da comunidade, que pode levar ao desligamento do agente em caso de denúncia por negligência (Lima e Moura, 2005), dificuldades de relacionamento com membros da comunidade ou no processo de trabalho dentro da equipe de saúde (Bernadino et al., 2005; Pedrosa e Teles, 2001).

Fortes e Spinetti (2004) mostram ainda que existe uma preocupação constante da equipe do PSF quanto à observação do princípio ético da privacidade sobre as informações dos usuários, dada a proximidade do agente com a comunidade, bem como a dificuldade de manutenção da privacidade do próprio agente. Os autores questionam se existiria uma esfera de confiabilidade entre agentes e comunidade e se todas as informações que os ACS 
recebem dos usuários em confiança devem ser repassadas aos outros elementos da equipe de saúde. Lembram ainda que, ao viver no mesmo local que trabalha, o ACS pode conviver, em várias regiões, com a violência organizada, como gangues e narcotráfico. Lima e Moura (2005) explicam que o grau de violência dificulta, pelo menos inicialmente, o trabalho dos agentes comunitários de saúde nas capitais dos estados e grandes cidades, onde são vistos com desconfiança pela população.

A falta de confiança entre os membros da equipe é apontada por Valentim e Kruel (2006) como um dos motivos que pode trazer conflitos durante o trabalho do ACS, com conseqüências para todo o relacionamento estabelecido com a equipe e com a comunidade.

\section{Considerações finais}

A experiência dos agentes comunitários de saúde recupera a idéia de sociabilidade, das redes e círculos sociais, confiança e outros conceitos que remetem à subjetividade dos indivíduos e das formas como se estabelecem e se reproduzem as relações sociais. Isto, de certa forma, se contrapõe à tendência à racionalização burocrática que estaria presente como resultado da complexificação das relações sociais no capitalismo. Permite, igualmente, analisar o surgimento de novas categorias de trabalhadores num contexto de transformações capitalistas e da discussão de formas de assalariamento e sua vinculação com direitos, produtos de lutas sociais do século XX.

Por um lado, temos um trabalhador valorizado por fazer parte da comunidade em que vive, recebe formação contínua e participa ativamente da política de saúde desenvolvida em sua área de atuação. Por outro, temos a comunidade que recebe um serviço do qual sempre fora excluída e passa a controlar, de certa forma, esse serviço, algo impensável na cultura do funcionalismo público. Esses seriam os aspectos positivos da flexibilização característica dessa categoria de trabalhador.

Temos ainda um trabalhador que corre o risco de, durante anos, manter-se com contratos por tempo determinado, às vezes sem contrato algum, sem estabilidade e sem perspectiva de futuro. Melhoria no serviço prestado e relações de trabalho precárias que, embora mais participativas e ricas enquanto atividade, mantêm o trabalhador num quadro de vulnerabilidade social.

No meio-termo, temos formas alternativas de contrato, como cooperativas, associações ou contratos pela CLT, com direitos restritos, mas sem o 'caráter', digamos, fordista do emprego público.

Se a situação atual está longe da ideal, um retorno à situação anterior,

pensada no quadro do funcionalismo, é complicada. Primeiro, porque o 
programa tem dado certo, com indicadores positivos que apontam para o acerto da relação comunidade e políticas públicas. Segundo, porque a universalidade prevista pelo estatuto do funcionalismo poderia eliminar o caráter comunitário da atividade, eliminando o 'capital social' do agente como fator fundamental para o êxito do programa pelo conhecimento que propicia do grupo a ser atendido.

A despeito das dificuldades encontradas na prática profissional do ACS, da atipicidade do seu trabalho e da vulnerabilidade social por eles enfrentada, o papel desempenhado por estes profissionais permanece central para a política de saúde nacional, atuando, segundo Kluthcovsky et al. (2007) como 'tradutor' do universo científico ao popular. Falta, contudo, propiciar a esse trabalhador contratos de trabalho que não precarizem sua atuação, sem comprometer o caráter comunitário que está em sua origem, estabelecendo parâmetros mais nítidos para que os direitos dos usuários não eliminem os dos trabalhadores.

\section{Notas}

1 Professor titular do Departamento de Sociologia da Universidade Federal de São Carlos (UFSCar), São Carlos, São Paulo, Brasil. Doutor em Sociologia pela Universidade de São Paulo (USP). Pós-doutor pelo Massachusetts Institute of Technology (MIT). $<$ jacobl@uol.com.br>

Correspondência: Departamento de Sociologia, Universidade Federal de São Carlos, Rodovia Washington Luís, Km 235 - SP-310, São Carlos, São Paulo, CEP 13.565-905.

2 Pesquisadora do Grupo de Estudos Trabalho e Mobilidade Social do Departamento de Sociologia da Universidade Federal de São Carlos (UFSCar), São Carlos, São Paulo, Brasil. Doutora em Engenharia de Produção pela Universidade Federal de São Carlos. $<$ cockell@dep.ufscar.br>

3 O Regime Jurídico Único determina funções e cargos dos servidores públicos de acordo com a lei $\mathrm{n}^{\circ} 8.112$, de 11 de dezembro de 1990.

${ }^{4} \mathrm{O}$ código 7 refere-se ao profissional autônomo no sistema hospitalar.

5 O Serviço Especial de Saúde Pública (Sesp) foi criado em 1942, sendo, posteriormente, transformado em fundação por força da lei n. ${ }^{\circ} 3.750$, de 11 de abril de 1960 . Visitadoras sanitárias, com nível médio, eram preparadas pela fundação para dar assistência interna no Centro de Saúde e, externa, nos domicílios, a gestantes, mães, crianças e doentes de moléstias contagiosas sob supervisão de enfermeiras (Mazza, 1994).

6 Em 2000, o Ministério da Saúde criou o incentivo de saúde bucal que proporcionou a inserção das Equipes de Saúde Bucal (ESB) na Estratégia Saúde da Família. As equipes já 
ampliadas passaram a contar ainda com: um dentista, um auxiliar de consultório dentário e um técnico em higiene dental (Brasil, 2008).

${ }^{7}$ Sobre o conceito de capital social, ver Bourdieu (1998) e Lima (2001).

8 De forma geral, as críticas concentram-se na incompletude do programa e dos gargalos provocados pela entrada no serviço sem possibilidades de atendimentos de maior complexidade; referências em grande medida corporativistas, como a considerada excessiva idealização do médico generalista ou da formação incompleta, o que ameaçaria profissionais de enfermagem e serviço social com uma precarização de atividades técnicas; até questões mais políticas sobre a natureza do trabalho.

${ }^{9}$ A vinculação institucional abrange, segundo Nogueira, Silva e Ramos (2000, p. 1), a “dimensão jurídica da relação de trabalho e a dimensão administrativa da relação institucional. A relação jurídica de trabalho pode ser dada pelo regime celetista, enquanto a relação institucional pode realizar-se mediante uma associação comunitária conveniada com a secretaria de saúde do município. As duas noções de relação - de trabalho e institucional - entram, assim, no conceito de vinculação institucional".

10 A busca foi realizada no site www.pciconcursos.com.br, no dia 23 de agosto de 2008, com as palavras-chave 'agente comunitário de saúde', 'concurso público', 'vagas', e '2008'.

\section{Referências}

ANDRADE, Luiz O. Monteiro; INOJOSA, Rose Marie. Saúde da família, violência e cultura da paz. Revista Brasileira de Saúde da Família, Brasília, v. 1, n. 7, p. 55-61, jan.-abr. 2004.

BACHILLI, Rosane Guimarães; SCAVASSA, Ailton José; SPIRI, Wilza Carla. A identidade do agente comunitário de saúde: uma abordagem fenomenológica. Ciência \& Saúde Coletiva, Rio de Janeiro, v. 13, n. 1, p. 51-60, 2008.

BERNARDINO, Mônica T. S. M. et al. Consensos e divergências: a capacitação profissional das equipes de saúde da família no município de São Carlos (SP). Trabalho, Educação e Saúde, Rio de Janeiro, v. 3, n. 1, p. 75-89, 2005.

BIAVASCHI, Magda Barros. O direito do trabalho no Brasil - 1930/1942: a construção do sujeito de direitos trabalhistas. Tese (Doutorado em Economia Aplicada). Campinas, Instituto de Economia, Unicamp, 2005.

BORNSTEIN, Vera Joana; STOTZ, Eduardo Navarro. Concepções que integram a formação e o processo de trabalho dos agentes comunitários de saúde: uma revisão da literatura. Ciência \& Saúde Coletiva, Rio de Janeiro, v. 13, n. 1, p. 259-268, 2008.

BOURDIEU, Pierre. O capital social: notas provisórias. In: BOURDIEU, Pierre. Escritos de educação. NOGUEIRA, Maria Alice; CATANI, Afrânio (Orgs.). Petrópolis: Vozes, 1998.

BRASIL. Portaria n.o 1.886, 18 de dezembro 1997. Aprova as normas e diretrizes do Pacs e PSF. Diário Oficial [da] República Federativa do Brasil, Brasília, DF, 19 dez. 1997. 
Ministério da Saúde. Saúde da Família: uma estratégia para a reorientação do modelo assistencial. Brasília: Ministério da Saúde, 1998.

Ministério da Educação. Educação profissional: referenciais curriculares nacionais da educação profissional de ensino técnico na área saúde, 2000. Disponível em: $<$ www.mec.gov.br/semtec/educprof/ftp/ Referenciais\% Curriculares/saúde.pdf $>$. Acesso em: 26 ago. 2008.

Lei $n .^{\circ} 10.507,10$ de julho de 2002. Cria a profissão de agente comunitário de saúde e dá outras providências. Diário Oficial [da] República Federativa do Brasil, Brasília, DF, 11 jul. 2002.

Ministério da Saúde. Modalidade de contratação de agentes comunitários de saúde: um pacto tripartite. Brasília, MSSecretaria de Políticas de Saúde, Departamento de Atenção Básica, 2002.

Ministério da Saúde. Ministério da Educação. Referencial curricular para curso técnico de agente comunitário de saúde: área profissional saúde. Brasília: Ministério da Saúde, 2004.

Ministério da Saúde. Sistema de Informação de Atenção Básica. 2005. Disponível em: <www.datasus.gov.br/siab/ siab.htm>. Acesso em: 4 ago. 2008.

Ministério da Saúde. Repasses para Saúde da Família aumentam a partir deste mês. 1 ago. 2007. Disponível em: $<$ http://sna.saude.gov.br/imprimir.cfm? $\mathrm{id}=3906>$. Acesso em: 17 ago. 2008.

Ministério da Saúde. Departamento de Atenção Básica. Atenção Básica e a Saúde da Família. Disponível em: $<$ http://dtr2004.saude.gov.br/dab/ atencaobasica.php>. Acesso em: 23 ago. 2008.

CÂMARA MUNICIPAL DE CURITIBA. Agentes comunitários conquistam insalubridade. Curitiba, 17 nov. 2005. Disponível em: <www.cmc.pr.gov.br/ass_det.php? not $=6109>$. Acesso em: 13 out. 2008.

CASTEL, Robert. As metamorfoses da questão social. Petrópolis: Vozes, 1998.

CASTRO, Janete Lima de; VILAR, Rosane Lúcia Alves; FERNANDES, Vicente Paula. Precarização do trabalho do agente comunitário de saúde: um desafio para a gestão do SUS. In: BARROS, André F. do Rêgo et al.(Orgs.). Observatório de Recursos Humanos em Saúde no Brasil. 1. ed. Brasília: Ministério da Saúde, 2004, v. 2, p. 105-120.

DESOTO, Hernando de. Economia subterrânea: uma análise da realidade peruana. Rio de Janeiro: Globo, 1987.

FORTES, Paulo A. de Carvalho; SPINETTI, Simone Ribeiro. O agente comunitário de saúde e a privacidade das informações dos usuários. Cadernos de Saúde Pública, Rio de Janeiro, n. 20, v. 5, p. 1.328-1.333, set.-out. 2004.

HARVEY, David. Condição pós-moderna. São Paulo: Loyola, 1993.

JARDIM, Tatiane Andrade. Morar e trabalhar na mesma comunidade: a realidade dos agentes comunitários de saúde. Dissertação (Mestrado em Ciências da Reabilitação). São Paulo: Faculdade de Medicina, USP, 2007.

KREIN, José Dari. Tendências recentes nas relações de emprego no Brasil: 1990-2005. Tese (Doutorado em Economia Social e do Trabalho). Campinas, Instituto de Economia, Unicamp, 2007.

KLUTHCOVSKY, Ana Cláudia G. C. et al. Avaliação da qualidade de vida geral de agentes comunitários de saúde: a contribuição relativa das variáveis sociodemográficas e dos domínios da qualidade de vida. Revista Psiquiatria do Rio Grande do Sul, Rio Grande do Sul, n. 29, v. 2, p. 176183, 2007.

LIMA, Jacob Carlos. A teoria do capital social na análise das políticas públicas. Politi- 
ca e Trabalho. Revista de Ciências Sociais, João Pessoa, n. 17, p. 46-63, set. 2001.

LIMA, Jacob Carlos; MOURA, Maria Carmo. Trabalho atípico e capital social: os agentes comunitários de saúde na Paraíba. Sociedade e Estado, Brasília, v. 20, n. 1, p. 103-133, jan.-abr. 2005.

LIPIETZ, Alan. Audácia: uma alternativa para o século XXI. São Paulo: Nobel, 1991.

MACHADO, Eduardo Gomes. Campeões, curingas e robôs: os funcionários e a reestruturação no Banco do Brasil. Dissertação (Mestrado em Sociologia). João Pessoa: PPGS-UFPB, 2002.

MAZZA, Maria Porto Rossetto. A visita domiciliária como instrumento de assistência de saúde. Revista Brasileira Crescimento Desenvolvimento Humano, São Paulo,v. 4, n. 2, p. 60-68, 1994. Disponível em:<www.fsp.usp.br/MAZZA.htm $>$. Acesso em: 14 out. 2008.

MOROSINI, Márcia Valéria; CORBO, Anamaria D'Andrea; GUIMARÃES, Cátia Corrêa. Agente comunitário de saúde no âmbito das políticas voltadas para a atenção básica: concepções do trabalho e da formação profissional. Trabalho, Educação e Saúde, Rio de Janeiro, v. 5, n. 2, p. 261-280, 2007.

NASCIMENTO, Cynthia Maria Barboza. Precarização do trabalho do agente comunitário de saúde: um estudo em municípios da região metropolitana do Recife. Monografia de especialização. Pós-Graduação latu sensu em Saúde Pública do Departamento de Saúde Coletiva, Recife, 2005.

NOGUEIRA, Roberto Passos. Estabilidade e flexibilidade: tensão de base nas novas políticas de recursos humanos em saúde. Divulgação em Saúde para Debates, n. 14, p. 18-22, ago. 1996.

Política de recursos humanos para a saúde: questões na área da gestão e regulação do trabalho. Relatório final. Seminários Política de Recursos Humanos para a
Saúde; Questões na Área da Gestão e Regulação do Trabalho, 1999. Disponível em: <http://www.opas.org.br/rh/publicacoes/ textos_apoio/pub04U3T10.pdf $>$. Acesso em: 6 set. 2008 .

NOGUEIRA, Roberto Passos; SILVA, Frederico Barbosa; RAMOS, Zuleide Vale Oliveira. A vinculação institucional de um trabalhador sui generis: o agente comunitário de saúde. Rio de Janeiro, Ipea, Texto para discussão n. ${ }^{\circ}$ 735, jun. 2000.

NUNES, Mônica Oliveira et al. O agente comunitário de saúde: construção da identidade desse personagem híbrido e polifônico. Cadernos de Saúde Pública, Rio de Janeiro, v. 18, n. 6, p. 1.639-1.646, nov.-dez., 2002.

OLIVEIRA, Francisco de. Nordeste anos 70: as hostes errantes. Novos Estudos Cebrap. São Paulo, v. 1, n. 1, dez. 1981.

PEDROSA, José Ivo Santos; TELES, João Batista Mendes. Consenso e diferenças em equipes do Programa Saúde da Família. Revista de Saúde Pública, v. 35, n. 3, p.303-11, 2001.

PORTES, Alejandro; CASTELLS, Manuel; BENTON, Lauren (Eds.). The Informal Economy: Studies in Advanced and Less Developed Countries. Baltimore, The John Hopkins University Press, 1989.

SANTOS, Karina Tonini et al. Agente comunitário de saúde: perfil adequado à rea-lidade do Programa Saúde da Família? Ciência \& Saúde Coletiva [periódico na Internet], 2008. Disponível em: $<$ www.cienciaesaudecoletiva.com.br $>$. Acesso em: 08 ago. 2008.

SANTOS, Lenir. A emenda constitucional n. ${ }^{\circ}$ 51/2006 e os agentes comunitários de saúde. Boletim de Recursos Humanos, Curitiba, Governet, v. 4, n. 33, p. 19-28, jan. 2008.

VALADARES, Carolina. Indicadores são melhores onde há Saúde da Família. Agência Saúde, Brasil, 12 ago. 2008. Disponível em: 
$<$ http://portal.saude.gov.br/portal/ aplicacoes/noticias/noticias_detalhe.c fm?co_seq_noticia $=52097>$. Acesso em: 19 ago. 2008 .

VALENTIM, Igor V. Lima; KRUEL, Alexandra Jochims. A importância da confiança interpessoal para a consolidação do Progra- ma de Saúde da Família. Ciência \& Saúde Coletiva, Rio de Janeiro, v. 12, n. 3, p.777-788, jun. 2007.

Recebido em 10/09/2008

Aprovado em 10/10/2008 



